\section{Human heart-type fatty acid-binding protein as an early diagnostic marker of doxorubicin cardiac toxicity}

\author{
Ashraf H. EIGhandour, 'Manal El Sorady, \\ Sahar Azab, ${ }^{2}$ Mohammed ElRahman ${ }^{3}$ \\ 'Hematology Unit, '2Cardiology \\ Department, Faculty of Medicine, \\ Alexandria University \\ ${ }^{3}$ Military Medical Academy, Alexandria, \\ Alexandria, Egypt
}

\section{Abstract}

Progressive cardiotoxicity following treatment with doxorubicin-based chemotherapy in patients with non-Hodgkin's lymphoma (NHL) may lead to late onset cardiomyopathy. So, early prediction of toxicity can lead to prevention of heart failure in these patients. The aim of this work was to investigate the role of $\mathrm{H}$ FABP as an early diagnostic marker of anthracycline-induced cardiac toxicity together with brain natriuretic peptide (BNP) as an indication of ventricular dysfunction in such patients. Our study was conducted on $40 \mathrm{NHL}$ patients who received 6 cycles of a doxorubicin containing chemotherapy protocol (CHOP), not exceeding the total allowed dose of doxorubicin $\left(500 \mathrm{mg} / \mathrm{m}^{2}\right)$. Ten healthy controls were included in our study. Human heart-type fatty acid-binding protein (H-FABP) was assessed 24 hours after the first cycle of CHOP. Plasma levels of BNP were estimated both before starting chemotherapy and after the last cycle of CHOP. Resting echocardiography was also performed before and at the end of chemotherapy cycles. The ejection fraction (EF) of 8 of our patients decreased below $50 \%$ at the end of the sixth cycle. Elevated levels of both H-FABP and BNP were found in all patients wth EF below $50 \%$ and both markers showed a positive correlation with each other. We concluded that $\mathrm{H}$ FABP may serve as a reliable early marker for prediction of cardiomyopathy induced by doxorubicin. Thus, in patients with elevated $\mathrm{H}$ FABP, alternative treatment modalities with no cardiac toxicity may be considered in order to prevent subsequent heart failure in these patients.

\section{Introduction}

Anthracyclines are highly efficacious antineoplastic agents but their utility is limited by progressive cardiotoxicity. They include doxorubicin, daunorubicin, epirubicin and idaru- bicin. ${ }^{1}$ Anthracyclines cause a dose-dependent cardiomyopathy that often leads to congestive heart failure. Late onset cardiomyopathy can appear months to years after treatment is completed. ${ }^{2}$ The mechanism underlying cardiotoxic effects of anthracyclines is generally accepted to be via formation of free radicals generated by iron-doxorubicin complexes that damage cardiac cellular membranes. ${ }^{3}$ Cardiac damage caused by anthracyclines is cumulative. With total doses of doxorubicin less than $500 \mathrm{mg} / \mathrm{m}^{2}$, heart failure is seen in less than $7 \%$ of cases. ${ }^{4}$

Human heart fatty acid-binding protein $(\mathrm{H}-$ FABP) is a small protein abundant in the cytosol, which is readily released into the circulation following myocardial damage. Recent studies in laboratories and the emergency department have shown that heart-type fatty acid-binding protein (H-FABP), a more recently developed cardiac biomarker, is able to detect myocardial damage as soon as one hour after onset of ischemia and, therefore, is regarded the earliest plasma marker available. ${ }^{5,6} \mathrm{~A}$ bedside test for H-FABP, providing results within $15 \mathrm{~min},{ }^{7}$ could potentially reduce diagnostic uncertainty for patients suspected of ACS in primary care. Recently, Setsuta and colleagues reported that elevated levels of $\mathrm{H}$ FABP were associated with subsequent cardiac events in patients with chronic heart failure due to a variety of causes. ${ }^{8}$ On the other hand, brain natriuretic peptide (BNP) is an amino acid peptide chiefly secreted by the ventricular myocardium in response to strain. Thus, it may be viewed as a marker of myocardial load and the plasma measurement of BNP is being used increasingly in the diagnosis, prognosis and monitoring of patients with congestive heart failure. ${ }^{9,10}$ Since heart failure is a complex clinical syndrome, a single biochemical marker may not reflect all of its characteristics. Thus, the serial and combined measurements of markers of myocyte injury may open new perspectives in heart failure. ${ }^{8}$ The aim of our work was to investigate the value of H-FABP as an early diagnostic marker of anthracyclineinduced cardiotoxicity together with BNP as an indicator of ventricular dysfunction in nonHodgkin's lymphoma patients receiving doxorubicin-based chemotherapy.

\section{Subjects and Methods}

Our study was conducted on 40 patients with non-Hodgkin's lymphoma who received 6 cycles of an anthracycline containing regimen (CHOP) with the following doses: ${ }^{11}$

Cyclophosphamide: $750 \mathrm{mg} / \mathrm{m}^{2}$ IV Day 1

Doxorubicin: $\quad 50 \mathrm{mg} / \mathrm{m}^{2} \quad$ IV Day 1

Vincristine: $\quad 1.4 \mathrm{mg} / \mathrm{m}^{2} \quad$ IV Day 1

Prednisone: $\quad 100 \mathrm{mg} / \mathrm{d} \quad$ P0 Days 1-5

This cycle was repeated every 21 days.
Correspondence: Ashraf ElGhandour,

Hematology Unit, Internal Medicine Department, Alexandria, Egypt

E-mail: a.elghandour@alexmed.edu.eg

Received for publication: 13 January 2009.

Revision received: 9 April 2009.

Accepted for publication: 17 April 2009.

This work is licensed under a Creative Commons Attribution 3.0 License (by-nc 3.0)

(C) Copyright A. ElGhandour et al., 2009

Licensee PAGEPress, Italy

Hematology Reviews 2009; 1:e6

doi:10.4081/hr.2009.e6

Patients' age ranged from 14 to 56 years with a mean of $36.2 \pm 10.02$ years. Twenty-two of them were males, while 18 were females. Ten age and sex-matched healthy controls with no history of cardiac problems were included in our study.

None of our patients had symptoms or signs of cardiac disease at presentation, nor had they undergone previous cardiac surgery. Patients with severe hepatic or renal disease or other medical conditions in which combination chemotherapy may be contraindicated were excluded from our study. Also, patients with early stage disease (stage I and non-bulky stage II) who are candidates for involved-field irradiation in addition to chemotherapy were excluded.

At presentation, full history and clinical examination, complete blood picture, bone marrow examination and lymph node biopsy were carried out in all patients. Routine laboratory investigations, ECG and echocardiography were also performed.

Blood samples were obtained for estimation of BNP before starting the first cycle of chemotherapy and after completion of the sixth cycle. Blood was withdrawn for assessment of $\mathrm{H}$ FABP within 24 hours of administration of doxorubicin in the first cycle of $\mathrm{CHOP}^{12} \mathrm{H}-\mathrm{FABP}$ was measured utilizing human cardiac fatty acid-binding protein ELISA test kit, Oxis research catalog number: 11230 , 0xis International Inc., Foster City, CA, USA. ${ }^{13}$ Re-evaluation of ECHO findings regarding the left ventricular ejection fraction and parameters of diastolic function ${ }^{14}$ was carried out after the end of the sixth cycle of chemo-therapy.

\section{Results}

Patients' data are summarized in Table 1. The mean age of our patients at presentation was $36.2 \pm 10.02$ years. Fifty-five percent were males, while $45 \%$ were females. All patients had normal ECG findings with no clinical evi- 
dence of heart failure prior to chemotherapy.

After completing the first cycle of CHOP, plasma levels of H-FABP were found to be elevated in 10 patients. After completion of the sixth cycle of chemotherapy, 8 of the 10 patients with elevated H-FABP showed a significant reduction in the left ventricular ejection fraction to levels below 50\% and the reduction in EF showed a significant correlation with H-FABP levels (Figure 1). Six of them also showed evidence of diastolic dysfunction in the form of impaired relaxation and an E/A ratio below 1. Two patients of those with postchemotherapy ejection fraction values less than $50 \%$ had clinical manifestations of heart failure. Fifteen of our patients (37.5\%) showed evidence of diastolic dysfunction after 6 cycles of chemotherapy but 3 of them already had E/A ratios below 1 when evaluated before starting chemotherapy. We divided our patients into two groups according to echocardiographic evidence of left ventricular systolic dysfunction after the sixth cycle of chemotherapy (Table 2): Group I; patients who had left ventricular ejection fraction levels below 50\%; Group II; patients who had no echocardiographic evidence of heart failure.

On comparing the mean plasma BNP values in both groups, we found that prior to chemotherapy, they did not show a significant difference (mean value group I 70.28 \pm 9.45 , group II $75.62 \pm 11.84$ ). After six cycles of chemotherapy, both groups differed significantly as regards plasma BNP, with the mean value in group I being $70.4 \pm 9.527$ and in group II being $260 \pm 18.51(p<0.001)$. There was also a significant elevation of BNP values in group II patients after chemotherapy and this elevation correlated significantly with the reduced ejection fraction in these patients (Figure 2). There were no patients in whom clinical cardiac failure occurred without an associated rise in the BNP level above the threshold value. From the 10 patients who exhibited elevated $\mathrm{H}$ FABP levels after the first chemotherapy cycle, 8 also showed high BNP levels at the end of the sixth cycle and both biochemical markers correlated positively with each other (Figure 3).

\section{Discussion}

Cardiotoxicity leading to congestive heart failure is a well-known complication of anthracyclines. Biochemical methods to assess and monitor cardiac function after anthracycline administration, if informative would be of utmost value. ${ }^{15}$ We examined the diagnostic role of human heart-type fatty acid binding protein and brain natriuretic peptide to predict the impairment of left ventricular function in NHL patients treated by CHOP. We also studied the correlations between the plasma concen-

Table 1. Biochemical markers and ECHO findings in our patients.

\begin{tabular}{lcccc} 
& N. & Minimum & Maximum & Mean \\
Age & 40 & 14 & 56 & $36.2 \pm 10.02$ \\
BNP before chemotherapy $(\mathrm{pg} / \mathrm{mL})$ & 40 & 50 & 89 & $71.35 \pm 10.04$ \\
\hline BNP after chemotherapy $(\mathrm{pg} / \mathrm{mL})$ & 40 & 50 & 280 & $108.32 \pm 77.66$ \\
H-FABP $(\mathrm{ng} / \mathrm{mL})$ & 40 & 8 & 30 & $17.25 \pm 6.44$ \\
\hline EF before chemotherapy (\%) & 40 & 58 & 72 & $65.57 \pm 4.04$ \\
EF after chemotherapy (\%) & 40 & 40 & 70 & $61.4 \pm 9.79$ \\
\hline
\end{tabular}

Table 2. Comparison between group I and II patients as regards BNP and H-FABP.

\begin{tabular}{|c|c|c|c|c|}
\hline & N. & Mean & $\mathrm{T}$ & $p$ \\
\hline $\begin{array}{ll}\text { Age } & \text { GI } \\
& \text { GII }\end{array}$ & $\begin{array}{c}32 \\
8\end{array}$ & $\begin{array}{c}38.84 \pm 10.02 \\
41.75 \pm 8.44\end{array}$ & -1.79 & 0.081 \\
\hline $\begin{array}{l}\text { BNP before chemotherapy }(\mathrm{pg} / \mathrm{mL}) \\
\text { GI } \\
\text { GII }\end{array}$ & $\begin{array}{c}32 \\
8\end{array}$ & $\begin{array}{l}70.28 \pm 9.45 \\
75.62 \pm 11.8\end{array}$ & -1.185 & 0.265 \\
\hline $\begin{array}{l}\text { BNP after chemotherapy }(\mathrm{pg} / \mathrm{mL}) \\
\text { GI } \\
\text { GII }\end{array}$ & $\begin{array}{c}32 \\
8\end{array}$ & $\begin{array}{l}70.4 \pm 9.52 \\
260 \pm 18.5\end{array}$ & -28.048 & $0.000^{*}$ \\
\hline $\begin{array}{l}\text { H-FABP }(n g / m L) \\
\text { GI } \\
\text { GII }\end{array}$ & $\begin{array}{c}32 \\
8\end{array}$ & $\begin{array}{l}13.84 \pm 2.68 \\
27.15 \pm 2.53\end{array}$ & -13.103 & $0.000 *$ \\
\hline $\begin{array}{l}\text { EF before chemotherapy (\%) } \\
\text { GI } \\
\text { GII }\end{array}$ & $\begin{array}{c}32 \\
8\end{array}$ & $\begin{array}{c}65.84 \pm 4.14 \\
64.5 \pm 3.66\end{array}$ & 0.903 & 0.384 \\
\hline $\begin{array}{l}\text { EF after chemotherapy (\%) } \\
\text { GI } \\
\text { GII }\end{array}$ & $\begin{array}{c}32 \\
8\end{array}$ & $\begin{array}{l}65.65 \pm 5.02 \\
44.37 \pm 2.97\end{array}$ & 15.47 & $0.000^{*}$ \\
\hline
\end{tabular}

* p Significant. GI: Patients with post chemotherapy EF above 50\%. GII: Patients with post- chemotherapy EF below 50\%.

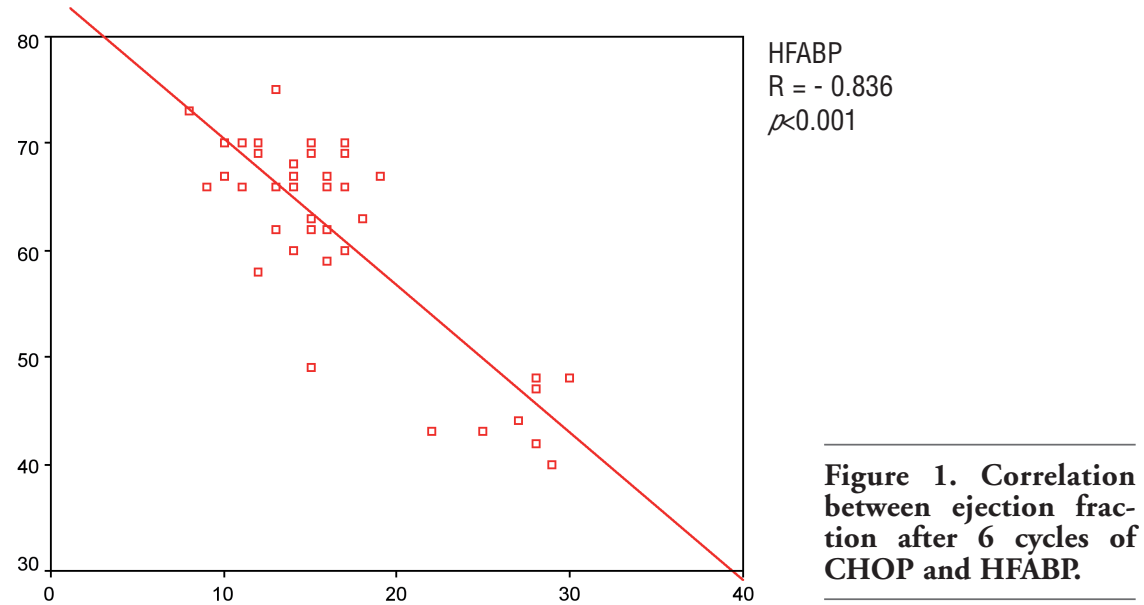

HFABP

trations of these biomarkers and the functional alterations associated with doxorubicin-induced myocardial damage. A significant correlation between the left ventricular ejection fraction after 6 cycles of CHOP and plasma levels of both HFABP and BNP was found in our patients. Pichon and colleagues stated that an infra-clinical cardiotoxicity of anthracyclines as defined by BNP elevation is frequent but reversible and that patients who developed heart failure showed a continuous BNP increase and concentrations over $100 \mathrm{ng} / \mathrm{mL}^{16}$ On the other hand, Daugaard and colleagues concluded that in spite of correlations between peptide concentrations and reduced ejection fraction values, neither baseline levels nor serial measurements can safely substitute EF monitoring in patients undergoing anthracycline therapy. ${ }^{10}$ Brain natriuretic peptide (BNP) was originally discovered in the porcine brain but was subsequently found to be predominantly a cardiac hormone. ${ }^{17}$ Unlike atrial 
natriuretic peptide (ANP), which is secreted by the atria in response to increased atrial pressure, BNP is derived chiefly from the cardiac ventricles in response to ventricular stresses. ${ }^{18}$ The plasma levels of both peptides are inversely correlated with measures of cardiac function and recent studies have shown BNP to be a more sensitive marker of cardiac impairment than ANP. ${ }^{19,20}$ Raised plasma BNP levels have previously been shown to herald the clinical picture of cardiac failure by days to weeks. ${ }^{21}$ Various guidelines based on changes in systolic and diastolic left ventricular function determined either by ECHO or by radionuclideventriculography (RVG) have been proposed for monitoring patients receiving anthracycline therapy. The advantages of ECHO over RVG are better availability, lower costs and lack of exposure to ionizing radiation. ${ }^{16}$ Although H-FABP is viewed as a marker of myocyte injury and BNP is considered indicative of ventricular strain, the finding that both markers correlated with each other in our patients shows that some degree of myocyte injury is associated with increased ventricular load. It is well-known that myocardial structure is also altered in congestive heart failure (CHF). Non-contiguous areas of myocardial cell death and foci of replacement fibrosis are typical morphological changes in advanced CHF. Therefore, cytosolic proteins may be released into the circulation through leakage due to increased permeability of the membranes of injured myocytes. ${ }^{22}$ Thus, the present study highlights the practical importance of measuring some biochemical markers such as plasma H-FABP and BNP to monitor left ventricular dysfunction in patients receiving anthracycline therapy as an early indication of subclinical cardiotoxicity.

\section{References}

1. Johnson SA, Richardson DS. Anthracyclines in haematology: pharmacokinetics and clinical studies. Blood Rev 1998; 12:52-71.

2. Kremer LC, van Dalen EC, Offringa M, et al. Anthracycline-induced clinical heart failure in a cohort of 607 children: longterm follow-up study. J Clin Oncol 2001; 19:191-6.

3. Shadle SE, Bammell BP, Cusack BJ, et al. Daunorubicin cardiotoxicity: evidence for the importance of the quinone moiety in a free-radical-independent mechanism. Biochem Pharmacol 2000;60:1435-44.

4. Coukell AJ, Faulds D. Epirubicin. An updated review of its pharmacodynamic and pharmacokinetic properties and therapeutic efficacy in the management of breast cancer. Drugs 1997;53:453-82.

5. Glatz JF, van der Vusse GJ, Simoons ML, et

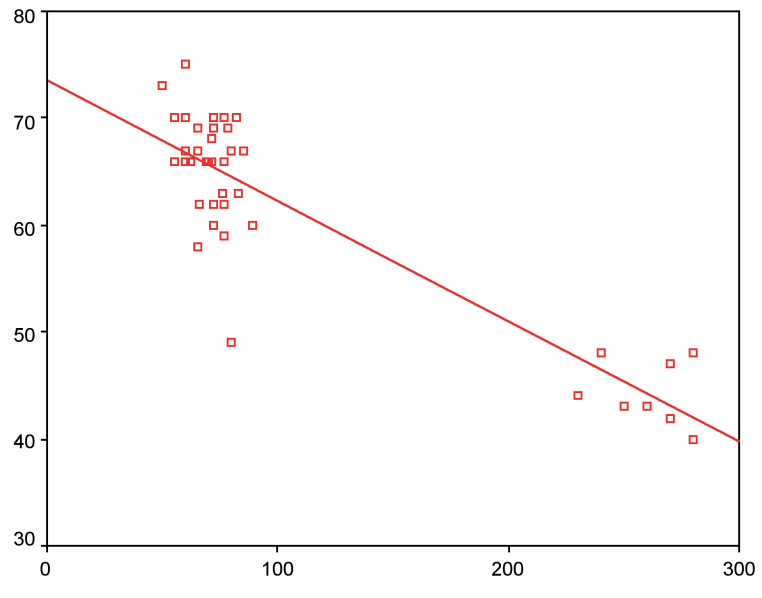

BNP

$\mathrm{R}=-0.892$

$p<0.001$

Figure 2. Correlation between ejection fraction after 6 cycles of CHOP and BNP levels.

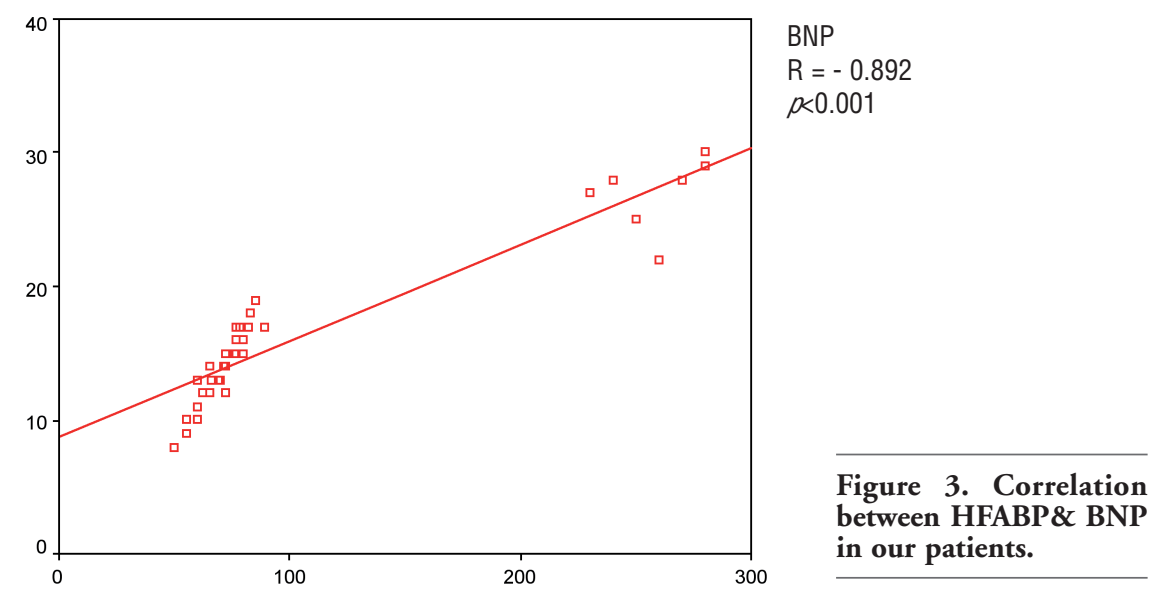

BNP

al. Fatty acid-binding protein and the early detection of acute myocardial infarction. Clin Chim Acta 1998;272:87-92.

6. van Nieuwenhoven FA, Kleine AH, Wodzig WH, et al. Discrimination between myocardial and skeletal muscle injury by assessment of the plasma ratio of myoglobin over fatty acid-binding protein. Circulation 1995;92:2848-54.

7. Chan CP, Sum KW, Cheung KY, et al. Development of a quantitative lateral-flow assay for rapid detection of fatty acid-binding protein. J Immunol Methods 2003; 279: 91-100.

8. Setsuta K, Seino Y, Ogawa T, et al. Ongoing myocardial damage in chronic heart failure is related to activated tumor necrosis factor and Fas/Fas ligand system. Circ J 2004;68:747-50.

9. Snowden JA, Hill GR, Hunt P, et al. Assessment of cardiotoxicity during hae- mopoietic stem cell transplantation with plasma brain natriuretic peptide. Bone Marrow Transplant 2000;26:309-13.

10. Daugaard G, Lassen U, Bie P, et al. Natriuretic peptides in the monitoring of anthracycline-induced reduction in left ventricular ejection fraction. Eur J Heart Fail 2005;7:87-93.

11. McKelvey EM, Gottlieb JA, Wilson HE, et al. Hydroxydaunomycin (adriamycin) combination chemotherapy in malignant lymphoma. Cancer 1976;38:1484-93.

12. Hermann-Arnhof KM, Hanusch-Enserer U, Kaestenbauer T, et al. N-terminal pro-Btype natriuretic peptide as an indicator of possible cardiovascular disease in severely obese individuals: comparison in patients with different stages of heart failure. Clin Chem 2005;51:138-43.

13. Wodzig KW, Pelsers MM, van der Vusse GJ, et al. One-step enzyme-linked immunosor- 
bent assay (ELISA) for plasma fatty acidbinding protein. Ann Clin Biochem 1997; 34:263-8.

14. Choy AJ, Darber D, Lang C, et al. Detection of left ventricular dysfunction after acute myocardial infarction: comparison of clinical, echocardiographic and neurohormonal methods. Br Heart J 1994;72:16-22.

15. Germanakis I, Kalmanti M, Parthenakis F, et al. Correlation of plasma $\mathrm{N}$-terminal pro-brain natriuretic peptide levels with left ventricle mass in children treated with anthracyclines. Int J Cardiol 2006;108:2125 .

16. Pichon MF, Cvitkovic F, Hacene K, et al. Drug-induced cardiotoxicity studied by longitudinal B-type natriuretic peptide assays and radionuclide ventriculography. In vivo 2005;19:567-76.

17. Mukoyama M, Nakao K, Hosoda K, et al. Brain natriuretic peptide as a novel cardiac hormone in humans. J Clin Invest 1991;87:1402-12.

18. Yasue H, Yoshimora M, Sumida H, et al. Localisation and mechanism of secretion of B-type natriuretic peptide in normal subjects and patients with heart failure. Circulation 1994;90:195-200.

19. Richards AM, Nicholis MG, Yandle TG, et al. Plasma N-terminal pro-brain natriuretic and adrenomedulin. New neurohormonal predictors of left ventricular function and prognosis after myocardial infarction. Circulation 1998;97:1921-9.
20. Davidson NC, Naas AA, Hanson JK, et al. Comparison of atrial natriuretic peptide, B-type natriuretic peptide, and N-terminal proatrial natriuretic peptide as indicators of left ventricular systolic dysfunction. Am J Cardiol 1996;77:828-31.

21. Hunt PJ, Richards AM, Nicholis MG. et al. Immunoreactive amino-terminal pro-brain natriuretic peptide (NT-proBNP): a new marker of cardiac disease. Clin Endocrinol 1997;47:287-96.

22. Schaper J, Froede R, Hein St, et al. Impairment of the myocardial ultrastructure and changes of the cytoskeleton in dilated cardiomyopathy. Circulation 1991; 83:50414. 